\title{
Predictors of severity of retinopathy among subjects with early onset type 2 diabetes mellitus
}

\author{
Thasni Mohammed ${ }^{1}$, Padma B. Prabhu ${ }^{2, *}$, Jyothi P T ${ }^{3}$ \\ ${ }^{1}$ Junior Resident, ${ }^{2}$ Associate Professor, ${ }^{3}$ Professor and HOD, Dept. of Ophthalmology, Government Medical College, Kozhikode, \\ Kerala, India
}

*Corresponding Author: Padma B. Prabhu

Email: padmapraveen@gmail.com

\begin{abstract}
Purpose: To explore the factors influencing the severity of diabetic retinopathy among early onset type 2 diabetes mellitus. Materials and Methods: A descriptive cross sectional study was undertaken among subjects with early onset type 2 diabetes mellitus diagnosed with retinopathy. Demographic profiles like age, gender, duration of diabetes, co-morbidities and presence of macrovascular or microvascular complications were noted. Retina was evaluated using slit lamp biomicroscopy using 78D lens and Spectral Optical Coherence Tomography (OCT).

Results: The study group included 135 subjects. There were 78 NPDR and 57 PDR cases. Those with PDR had higher age, longer duration of diabetes, lower $\mathrm{Hb}$ values, higher $\mathrm{HbA1C}$ and higher urine micro-albumin. They had a higher triglyceride values and lower HDL values.

Conclusion: Higher age, longer duration, anemia, poor glycemic control and subclinical nephropathy were predictive of development of PDR among early onset type 2 DM subjects.
\end{abstract}

Keywords: Early onset diabetes mellitus, NPDR, HbA1C, PDR, Urine micro-albumin.

\section{Introduction}

Retinopathy is the leading cause of blindness among persons with diabetes. Various factors have been identified as predictors of development of diabetic retinopathy and its progression. Most of the studies have been conducted among type 1 and late onset type 2 diabetes. This study intends to explore the factors influencing the severity of diabetic retinopathy among early onset (age of onset <40 years) Type 2 diabetes mellitus.

\section{Materials and Methods}

A descriptive cross sectional study was conducted after obtaining permission from the Institutional Research \& Ethics Committee. Sample size of 122 was calculated based on the formula $4 \mathrm{pq} / \mathrm{d} 2$ where $\mathrm{p}=45$, $\mathrm{d}=20 \%$ of $\mathrm{p}$.

Subjects diagnosed with retinopathy among cases of early onset Type 2 diabetes mellitus (age of onset before 40 years) were selected. Juvenile diabetes mellitus, gestational diabetes mellitus, pancreatic diseases, other causes for endocrinopathies, steroid induced diabetes and genetic syndromes were excluded.

Demographic profiles like age, gender, socioeconomic status, duration of diabetes, comorbidities like smoking, alcoholism, hypertension, obesity and hyperlipidemia were recorded. Presence of macrovascular (coronary artery disease, cerebrovascular events, peripheral vascular disease) and microvascular complications (neuropathy, nephropathy, and retinopathy) were noted. The subjects were grouped based on the presence or absence of at least one complication other than retinopathy). Retina was evaluated using slitlamp biomicroscopy using 78D lens and Spectral Optical Coherence Tomography (OCT). The status of the eye with worst retinopathy was considered for analysis.

$\mathrm{Hb}$, fasting blood sugar (FBS), postprandial blood sugar (PPBS), glycosylated $\mathrm{Hb}$ level (HbA1C), blood urea, serum creatinine, urine micro-albumin and fasting lipid profile were recorded.

Based on ETDRS classification diabetic retinopathy was grouped as non proliferative diabetic retinopathy (NPDR) \& proliferative diabetic retinopathy (PDR). NPDR was diagnosed by the presence of atleast one microaneurysm in the retina. Other findings seen in NPDR included hemorrhages, venous changes like dilatation, beading \& looping, cotton wool spots and intraretinal microvascular anomalies. PDR was diagnosed by the presence of neovascularisation of retina. Other changes like preretinal hemorrhage, vitreous hemorrhage and fibrovascular changes also were observed in PDR. Statistical analysis was done using SPSS version 21. Independent $\mathrm{T}$ test was used to analyse the parameters. $\mathrm{P}$ value less than 0.05 was considered statistically significant.

\section{Results}

The study group included 135 subjects. There were 78 cases with NPDR and 57 cases with PDR. Distribution of cases based on the demographic profile is given in Table 1. Those with PDR had higher age and longer duration of diabetes $(p<0.05)$. Age of onset of the subjects with PDR was less than those with NPDR. However this was not statistically significant.

Distribution of cases based on risk factors and complications is given in Table 2. Microvascular complications were found to be more among those with 
PDR. This observation was statistically significant $(\mathrm{p}$ 0.037).

Distribution of cases based on lab parameters is given in Table 3. Those with PDR had lower Hb values, higher $\mathrm{HbA} 1 \mathrm{C}$ and higher urine micro-albumin. They had a higher triglyceride values and lower HDL values. These observations were statistically significant.

Those with NPDR were classified as mild, moderate, severe and very severe NPDR. PDR was grouped as early PDR, high risk PDR and advanced diabetic eye disease. The various parameters $(\mathrm{Hb}$, $\mathrm{HbA} 1 \mathrm{C}$, urine micro-albumin, fasting lipid profile) were studied in relation to these subgroups. No statistically significant observations were made.

On multivariate regression analysis, duration of diabetes (beta error $0.7 ; \mathrm{p}$ value 0.002 ), $\mathrm{Hb} \mathrm{gm} \%$ (beta error 3.4; $p$ value 0.021 ) and $\mathrm{HbA} 1 \mathrm{C}$ (beta error $3.1 ; \mathrm{p}$ value 0.011 ) values were predictive on the development of proliferative diabetic retinopathy with overall fit of the model $\mathrm{R}^{2}$ 14.4.

\section{Discussion}

Severity of retinopathy in the form of proliferative diabetic retinopathy was associated with older age, earlier age of onset and longer duration of the disease. The mean age of subjects with PDR was higher than those with NPDR. Age of onset was lesser among those with PDR. This is reflective of the role of duration in the progression of the disease. There was no gender predilection. As the duration increased, the disease severity also increased. Tariq et al considers age group 41-50 years, male gender and positive family history of Diabetes Mellitus as predictors of severity of DR. ${ }^{1}$ This is also in concordance with Song et al. $^{2}$ These researchers have suggested duration as an important predictor of retinopathy. This observation is significant even among late onset DM as reported by Henricson et al and Zhang et al. ${ }^{3,4}$ Ahamed Razia et al observed that retinopathy was higher among patients who had developed diabetes at younger age $(<45$ years) compared with patients who developed diabetes beyond 45 years. Duration was a strong predictor for DR. ${ }^{5}$ Leese et al found that duration of diabetes is a strong predictor for maculopathy and proliferative disease. ${ }^{6}$

Hypertension was not associated with severity of retinopathy. Hypertension has been closely associated with the onset, progression and severity of retinopathy among early onset diabetics. Various authors (Song et al, Jin $\mathrm{P}$ et al, Anan $\mathrm{F}$ et al, Son JW et al) have mentioned this association. ${ }^{2,7-9}$ Forga $\mathrm{L}$ et al, Zhang et al, He BB et $\mathrm{al}$ and $\mathrm{Hu} \mathrm{M}$ et al have observed similar relation between hypertension and retinopathy among older onset diabetics. ${ }^{10,4,11,12}$ Lima et al observed that association between hypertension and DR varies in consistency and pattern. ${ }^{13}$ Zheng et al concluded that isolated pressure measurements may not accurately represent continued effect of high pressure. ${ }^{14}$ Ahamed et al noted that co existence of hypertension and nephropathy also appeared as significant predictor. ${ }^{15}$ Leese et al noted that raised systolic blood pressure was a predictor of maculopathy. Even in absence of established hypertension, changes in homeostasis of blood pressure levels are considered as a co morbidity associated with the presence and severity of DR.

Microvascular complications were more among PDR. However associations between neuropathy and nephropathy with the severity of retinopathy could not be defined. Malagola $\mathrm{R}$ et al concluded that early onset type 2 diabetes mellitus had much higher risk of microvascular complications than matched control with Type I diabetes in spite of good glycemic control. ${ }^{16}$ Ding $\mathrm{j}$ et al considers retinal vessel caliber as a potential tool to determine the incidence and progression of retinopathy in both Type I and Type 2 Diabetes mellitus. They concluded that among young type I diabetes narrow arteriolar caliber were consistently associated with PDR. ${ }^{17}$

It was observed that those with PDR were anemic. Association of anemia with diabetic retinopathy has been reported among elderly diabetics even without nephropathy. (Bahar A et al and Traveset et al). ${ }^{18,19}$ They observed a prevalence of 26 to $56 \%$ among their study group. Bhaisakhiya et al noted that unrecognized anemia exists in diabetic subjects. The severity of anemia was greater in subjects with retinopathy. ${ }^{20}$ Similar observation was made by Hosseni M S et al. ${ }^{21}$

HbA1C was more than normal among both NPDR and PDR. A statistically significant higher value was observed among PDR cases. Lima et al noted that hyperglycemia has a strong association with DR. Ahamed et al reported that glycemic control status of diabetic patient is a significant predictor of DR. According to Hoque et al, HbA1c categories $>7.0 \%$ is an important risk factor for the development of retinopathy. Poor glycaemic control, advanced age, longer duration of diabetes and hypertension are other significant risk factors of diabetic retinopathy. ${ }^{22}$ Yau J W et al also observed that longer diabetes duration and poorer glycemic and blood pressure control are strongly associated with DR. ${ }^{23}$ Song et al found that higher proportion of early onset Type 2 diabetes mellitus subjects had suboptimal glycaemic control (HbA1C $>7.5 \%$ ) than late onset cohort. ${ }^{24}$ Similar observations were made by Wilmot et al, Hussain $\mathrm{S}$ et al and $\mathrm{Xu} \mathrm{Y}$ et al. ${ }^{25-27}$ Niveditha $\mathrm{H}$ et al observed that those with raised HbA1C $>8 \%$ developed PDR. ${ }^{28}$ Blood urea and serum creatinine also showed a significant relation with severity of retinopathy. Leese et al suggests that raised HbA1C was important for developing proliferative retinopathy.

PDR was significantly associated with higher urine micro-albumin levels. Role of microalbuminuria as a marker of microvascular dysfunction and presence of DR has been reported. However further studies are needed to confirm this relationship with regard to the severity and type of diabetic retinopathy. ${ }^{6,7,12,14}$ 
The subjects also had high triglyceride and lower high density lipoprotein levels. Role of hyperlipedemia in prognosticating the severity of retinopathy is not yet defined. Mukherjee et al noted that apo B-100, total cholesterol, triglycerides and LDL cholesterol were the highest in severe NPDR cases. ${ }^{29}$ Though hyperlipedemia and hypertriglyceridemia has been associated with onset of retinopathy and maculopathy its effect on the development of PDR is not extensively studied. $6,8,26,30$ Ding $\mathbf{J}$ et al reports that dyslipidemia was a significant risk factor for development of diabetic macular edema in upto $7 \%$ cases. ${ }^{17}$

\section{Conclusion}

Among young adults with early onset of diabetes mellitus, severity of retinopathy was associated with older age, earlier age of onset and longer duration of the disease. Microvascular complications were more among PDR. Anemia, poor glycemic control and elevated urine micro-albumin were predictive of PDR. Hypertriglyceredemia and lower levels of HDL cholesterol were observed among PDR cases.

Table 1: Demographic profiles of subjects with NPDR and PDR

\begin{tabular}{|c|c|c|c|c|c|c|c|c|c|}
\hline \multirow{2}{*}{\multicolumn{2}{|c|}{$\begin{array}{l}\text { Significant } \\
\text { Variables }\end{array}$}} & & \multicolumn{6}{|c|}{ Type of retinopathy } & \multirow[t]{2}{*}{$P$ value } \\
\hline & & & \multicolumn{3}{|c|}{ NPDR (N2 78) } & \multicolumn{3}{|c|}{ PDR (N2 57) } & \\
\hline \multicolumn{2}{|c|}{ Age (years) } & & \multicolumn{3}{|c|}{46.85 (SD 8.58) } & \multicolumn{3}{|c|}{47.44 (SD 6.76) } & 0.015 \\
\hline \multicolumn{2}{|c|}{ Age of onset (years) } & & \multirow{2}{*}{\multicolumn{3}{|c|}{$\frac{33.13(\text { SD } 5.85)}{14.22(\text { SD } 7.25)}$}} & \multicolumn{3}{|c|}{31.54 (SD 6.02) } & $\mathrm{NS}$ \\
\hline \multicolumn{2}{|c|}{ Duration (years) } & & & \multicolumn{2}{|c|}{$14.22($ SD 7.25$)$} & \multicolumn{3}{|c|}{15.55 (SD 6.31) } & 0.001 \\
\hline & & N1 & $\mathrm{n}$ & $\mathrm{N} 1 \%$ & $\mathrm{~N} 2 \%$ & $\mathrm{~N}$ & $\mathrm{~N} 1 \%$ & $\mathrm{~N} 2 \%$ & \\
\hline \multirow[t]{2}{*}{ Gender } & Male & 84 & 47 & $55.95 \%$ & $60.25 \%$ & 37 & $44.04 \%$ & $64.91 \%$ & NS \\
\hline & Female & 51 & 31 & $60.78 \%$ & $39.74 \%$ & 20 & $39.21 \%$ & $35.08 \%$ & NS \\
\hline
\end{tabular}

NS - Not significant; N1\% $=(\mathrm{n} / \mathrm{N} 1) \times 100 ; \mathrm{N} 2 \%=(\mathrm{n} / \mathrm{N} 2) \times 100$

Table 2: Risk factors and complications in subjects with NPDR and PDR

\begin{tabular}{|c|c|c|c|c|c|c|c|c|}
\hline \multirow{3}{*}{$\begin{array}{l}\text { Risk factors } \\
\text { \& complications }\end{array}$} & \multirow{3}{*}{ N1 } & \multicolumn{6}{|c|}{$\begin{array}{c}\text { Type of Retinopathy } \\
\end{array}$} & \multirow{3}{*}{$P$ value } \\
\hline & & \multicolumn{3}{|c|}{ NPDR (N2=78) } & \multicolumn{3}{|c|}{ PDR (N2=57) } & \\
\hline & & $\mathrm{n}$ & $\mathrm{N} 1 \%$ & $\mathrm{~N} 2 \%$ & $\mathrm{n}$ & $\mathrm{N} 1 \%$ & $\mathrm{~N} 2 \%$ & \\
\hline Poor diabetic control & 129 & 75 & $58.13 \%$ & $96.15 \%$ & 54 & $41.86 \%$ & $94.73 \%$ & NS \\
\hline Microvascular comp. & 67 & 37 & $55.22 \%$ & $47.43 \%$ & 30 & $44.77 \%$ & $52.63 \%$ & 0.037 \\
\hline Neuropathy & 3 & 1 & $33.33 \%$ & $1.28 \%$ & 2 & $66.66 \%$ & $3.50 \%$ & NS \\
\hline Nephropathy & 64 & 37 & $57.81 \%$ & $47.43 \%$ & 27 & $42.18 \%$ & $47.36 \%$ & NS \\
\hline $\begin{array}{l}\text { Macrovascular } \\
\text { complications }\end{array}$ & 18 & 6 & $33.33 \%$ & $7.69 \%$ & 12 & $66.66 \%$ & $21.05 \%$ & NS \\
\hline Cerebrovascular accidents & 4 & 0 & - & - & 4 & $100 \%$ & $7.01 \%$ & NS \\
\hline Coronary artery disease & 12 & 6 & $50 \%$ & $7.69 \%$ & 6 & $50 \%$ & $10.52 \%$ & NS \\
\hline $\begin{array}{l}\text { Peripheral vascular } \\
\text { disease }\end{array}$ & 2 & 0 & - & - & 2 & $100 \%$ & $3.50 \%$ & NS \\
\hline $\begin{array}{l}\text { Presence of at least one co } \\
\text { morbidity }\end{array}$ & 94 & 55 & $58.51 \%$ & $70.51 \%$ & 39 & $41.48 \%$ & $68.42 \%$ & NS \\
\hline a)Smoking & 19 & 9 & $47.36 \%$ & $11.53 \%$ & 10 & $52.63 \%$ & $17.54 \%$ & NS \\
\hline b)Alcoholism & 4 & 3 & $75 \%$ & $3.84 \%$ & 1 & $25 \%$ & $1.75 \%$ & NS \\
\hline c)Hypertension & 60 & 35 & $58.33 \%$ & $44.87 \%$ & 25 & $41.66 \%$ & $43.85 \%$ & NS \\
\hline d)Hyperlipidemia & 49 & 26 & $53.06 \%$ & $33.33 \%$ & 23 & $46.93 \%$ & $40.35 \%$ & NS \\
\hline Multiple co morbidities & 84 & 49 & $58.33 \%$ & $62.82 \%$ & 35 & $41.66 \%$ & $61.40 \%$ & NS \\
\hline
\end{tabular}

NS - Not significant; N1\% = (n/N1) x 100; N2\% = (n/N2) x 100

Table 3: Lab parameters among NPDR and PDR

\begin{tabular}{|l|c|c|c|c|}
\hline \multicolumn{1}{|c|}{ Variables } & $\begin{array}{c}\text { Type of } \\
\text { retinopathy }\end{array}$ & Mean & SD & P Value \\
\hline $\mathrm{Hb} \mathrm{gm} \mathrm{\%}$ & NPDR & 12 & 1.45 & 0.05 \\
& PDR & 10.75 & 1.55 & NS \\
\hline $\mathrm{ESR} \mathrm{mm} / \mathrm{hr}$ & NPDR & 33.31 & 26.14 & 0.04 \\
\hline $\mathrm{HbA1C} \%$ & PDR & 37.26 & 23.08 & \\
& NPDR & 8.41 & 1.31 & 1.649 \\
\hline
\end{tabular}




\begin{tabular}{|c|c|c|c|c|}
\hline B.urea mg \% & $\begin{array}{c}\text { NPDR } \\
\text { PDR }\end{array}$ & $\begin{array}{l}39.29 \\
36.25\end{array}$ & $\begin{array}{l}24.71 \\
17.59\end{array}$ & NS \\
\hline S.creatinine $\mathrm{mg} \%$ & $\begin{array}{c}\text { NPDR } \\
\text { PDR }\end{array}$ & $\begin{array}{l}1.65 \\
1.65\end{array}$ & $\begin{array}{l}1.236 \\
1.142\end{array}$ & NS \\
\hline $\begin{array}{l}\text { Urine micro-albumin } \\
\mathrm{mg} / \mathrm{dl}\end{array}$ & $\begin{array}{c}\text { NPDR } \\
\text { PDR }\end{array}$ & $\begin{array}{l}41.72 \\
58.87\end{array}$ & $\begin{array}{l}31.01 \\
65.87\end{array}$ & 0.036 \\
\hline $\begin{array}{ll}\text { Total } & \text { cholesterol } \\
\mathrm{mg} \% & \end{array}$ & $\begin{array}{c}\text { NPDR } \\
\text { PDR }\end{array}$ & $\begin{array}{l}192.45 \\
195.39\end{array}$ & $\begin{array}{l}36.06 \\
41.98\end{array}$ & NS \\
\hline T G & $\begin{array}{c}\text { NPDR } \\
\text { PDR }\end{array}$ & $\begin{array}{l}133.59 \\
146.82 \\
\end{array}$ & $\begin{array}{l}51.30 \\
68.20 \\
\end{array}$ & 0.033 \\
\hline LDL & $\begin{array}{c}\text { NPDR } \\
\text { PDR }\end{array}$ & $\begin{array}{l}116.47 \\
120.12\end{array}$ & $\begin{array}{l}34.02 \\
37.52\end{array}$ & NS \\
\hline VLDL & $\begin{array}{c}\text { NPDR } \\
\text { PDR }\end{array}$ & $\begin{array}{l}29.10 \\
30.23\end{array}$ & $\begin{array}{c}9.64 \\
10.79\end{array}$ & NS \\
\hline HDL & $\begin{array}{c}\text { NPDR } \\
\text { PDR }\end{array}$ & $\begin{array}{l}45.99 \\
44.40 \\
\end{array}$ & $\begin{array}{l}6.22 \\
8.19 \\
\end{array}$ & 0.021 \\
\hline ratio & $\begin{array}{c}\text { NPDR } \\
\text { PDR }\end{array}$ & $\begin{array}{l}4.32 \\
4.30\end{array}$ & $\begin{array}{l}0.83 \\
1.11\end{array}$ & NS \\
\hline $\mathrm{Na}$ meq/l & $\begin{array}{c}\text { NPDR } \\
\text { PDR }\end{array}$ & $\begin{array}{l}139.62 \\
140.65\end{array}$ & $\begin{array}{l}4.81 \\
4.13\end{array}$ & NS \\
\hline $\mathrm{K}$ meq/l & $\begin{array}{c}\text { NPDR } \\
\text { PDR }\end{array}$ & $\begin{array}{l}4.45 \\
4.42 \\
\end{array}$ & $\begin{array}{l}0.71 \\
0.56 \\
\end{array}$ & NS \\
\hline
\end{tabular}

NS - Not significant

\section{References}

1. Tariq N. Association of Diabetes with Various Risk Factors. Journal of Islamabad Medical \& Dental College. 2017;6(1):44-8.

2. Song SH, Hardisty CA. Early onset type 2 diabetes mellitus: a harbinger for complications in later years-clinical observation from a secondary care cohort. QJM. 2009;102(11):799-806.

3. Henricsson M, Nilsson A, Groop L, Heijl A, Janzon L. Prevalence of diabetic retinopathy in relation to age at onset of the diabetes, treatment, duration and glycemic control. Acta Ophthalmologica. 1996;74(6):523-7.

4. Zhang X, Saaddine JB, Chou CF, Cotch MF, Cheng YJ, Geiss LS, Gregg EW, Albright AL, Klein BE, Klein R. Prevalence of diabetic retinopathy in the United States, 2005-2008. Jama. 2010;304(6):649-56.

5. Ahamed Razia A, Khalil Shamsun N, Al-Qahtani Mohammad AA. Diabetic retinopathy and the associated risk factors in diabetes type 2 patients in Abha, Saudi Arabia. Journal of Family \& Community Medicine. 2016;23(1):18-24.

6. Leese G. Longitudinal study examining the risk factors for proliferative retinopathy and maculopathy in type-I diabetes: the Royal College of Physicians of Edinburgh Diabetes Register Group. Eye. 2004;18(8):814.

7. Jin P, Peng J, Zou H, Wang W. The 5-year onset and regression of diabetic retinopathy in Chinese type 2 diabetes patients. PLoSne. 2014;9(11): e113359.

8. Anan F, Masaki T, Ito Y, Eto T. Diabetic retinopathy is associated with visceral fat accumulation in Japanese type 2 diabetes mellitus patients. Metabolism. 2010;59(3):314319.

9. Son JW, Jang EH, Kim MK, Kim IT, Roh YJ, Baek KH, Song KH, Yoon KH, Cha BY, Lee KW, Son HY. Diabetic retinopathy is associated with subclinical atherosclerosis in newly diagnosed type 2 diabetes mellitus. Diabetes Research and Clinical Practice. 2011;91(2):253-9.
10. Forga L, Goni MJ, Ibanez B, Cambra K. Influence of Age at Diagnosis and Time-Dependent Risk Factors on the Development of Diabetic Retinopathy in Patients with Type 1 Diabetes Journal of Diabetes Research. 2016(2016), Article ID 9898309, 7 pages.

11. He BB, Wei L, Gu YJ, Han JF, Li M, Liu YX, Bao YQ, Jia WP. Factors associated with diabetic retinopathy in chinese patients with type 2 diabetes mellitus. International Journal of Endocrinology. 2012;2012.

12. Hu M, Wan Y, Yu L, Yuan J, Ma Y, Hou B, Jiang X, Shang L. Prevalence, Awareness and Associated Risk Factors of Diabetes among Adults in Xi' an, China. Scientific Reports. 2017;7(1):10472.

13. Lima VC, Cavalieri GC, Lima MC, Nazario NO, Lima GC. Risk factors for diabetic retinopathy: a case-control study. International Journal of Retina and Vitreous. 2016;2(1):21.

14. Zheng W. Factor analysis of diabetic retinopathy in Chinese patients. Diabetes Res Clin Pract. 2011;92(2):244-52.

15. Ahmed KR, Karim MN, Bukht MS, Bhowmik B, Acharyya A, Ali L, Hussain A. Risk factors of diabetic retinopathy in Bangladeshi type 2 diabetic patients. Diabetes \& Metabolic Syndrome: Clinical Research \& Reviews. 2011;5(4):196-200.

16. Malagola R, Giannotti R, Arrico L. OCT: Macular thickness in insulin-dependent patients without evident retinopathy: a preliminary study. Clin Ter. 2012;163(6):e393-6.

17. Ding J, Ikram MK, Cheung CY, Wong TY. Retinal vascular calibre as a predictor of incidence and progression of diabetic retinopathy. Clinical and Experimental Optometry. 2012;95(3):290-6.

18. Bahar A, Kashi Z, Amiri AA, Nabipour M. Association between diabetic retinopathy and hemoglobin level. Caspian Journal of Internal Medicine. 2013;4(4):759. 
19. Traveset A, Rubinat E, Ortega E, Alcubierre N, Vazquez B, Hernández M, Jurjo C, Espinet R, Ezpeleta JA, Mauricio D. Lower hemoglobin concentration is associated with retinal ischemia and the severity of diabetic retinopathy in type 2 diabetes. Journal of Diabetes Research. 2016;2016.

20. Baisakhiya S, Garg P, Singh S. Anemia in patients with type II diabetes mellitus with and without diabetic retinopathy. International Journal. 2017;6(2):303.

21. Hosseini MS, Rostami Z, Saadat A, Saadatmand SM Anemia and Microvascular Complications in Patients with Type 2. Diabetes Mellitus Nephrourol Mon. 2014;6(4):e19976.

22. Hoque S, Muttalib MA, Islam MI, Khanam PA, Choudhury S. Evaluation of HbA1c Level and Other Risk Factors in Diabetic Retinopathy: A Study of Type 2 Diabetic Patients Attending in a Tertiary Level Hospital. KYAMC Journal. 2017;6(2):614-9.

23. Yau JW, Rogers SL, Kawasaki R, Lamoureux EL, Kowalski JW, Bek T, Chen SJ, Dekker JM, Fletcher A, Grauslund J, Haffner S. Global prevalence and major risk factors of diabetic retinopathy. Diabetes Care. 2012:DC_111909.

24. Song SH, Gray TA. Early-onset type 2 diabetes: high risk for premature diabetic retinopathy. Diabetes Res Clin Pract. 2011;94(2):207-211.

25. Wilmot E, Idris I. Early onset type 2 diabetes: risk factors, clinical impact and management. Therapeutic advances in chronic disease. 2014;5(6):234-44.

26. Hussain S, Qamar MR, Iqbal MA, Ahmad A, Ullah E. Risk factors of retinopathy in type 2 diabetes mellitus at a tertiary care hospital, Bahawalpur Pakistan. Pakistan Journal of Medical Sciences. 2013;29(2):536.

27. Xu Y, Wang L, He J, Bi Y, Li M, Wang T, Wang L, Jiang Y, Dai M, Lu J, Xu M. Prevalence and control of diabetes in Chinese adults. Jama. 2013;310(9):948-59.

28. Niveditha H, Yogitha C, Liji P, Sundeep S, Himamshu NV, Vinutha BV, Pooja P. Clinical correlation of HbA1c and diabetic nephropathy with diabetic retinopathy. Journal of Evolution of Medical and Dental Sciences. 2013;2(49):9430-6.

29. Giloyan A, Harutyunyan T, Petrosyan V. The prevalence of and major risk factors associated with diabetic retinopathy in Gegharkunik province of Armenia: crosssectional study BMC Ophthalmol. 2015;15:46.

30. Mukherjee B, Shankar S, Ahmed R, Singh K, Bhatia K. Association of Glycated Haemoglobin and Serum Apolipoproteins with Diabetic Re.tinopathy: An Indian Overview. Journal of Clinical and Diagnostic Research: JCDR. 2017;11(9):BC19.

How to cite this article: Mohammed T, Prabhu P. B, Jyothi P T. Predictors of severity of retinopathy among subjects with early onset type 2 diabetes mellitus. Indian $\mathrm{J}$ Clin Exp Ophthalmol. 2018;4(4):478-482. 